\title{
Jejunal Transport in Experimental Nephrotic Syndrome
}

\author{
MELINDA MCVICAR, ${ }^{(47)}$ JOSEPH MOR, RAUL A. WAPNIR, SAUL TEICHBERG, AND \\ FIMA LIFSHITZ
}

\author{
North Shore University Hospital, Departments of Pediatrics and Laboratories, Manhasset, New York 11030 and \\ Cornell University Medical College, Department of Pediatrics, New York, New York, 10021, USA
}

\begin{abstract}
Summary
In vivo jejunal transport of amino acids, monosaccharides, sodium, and electrolytes were studied in rats made nephrotic with puromycin aminonucleoside (PAN) and in pair-fed controls. Studies were performed 14 days after a single intravenous dose of PAN when rats were no longer edematous, but were still hypoproteinemic. There was decreased absorption of glucose, 3-0-methyl glucose, glycine, phenylalanine, histidine, water, and sodium in the nephrotic animals but transport of fructose, lysine and potassium was similar in the nephrotic and control animals. Enzyme kinetic studies for glucose transport showed a mixed type of inhibition affecting both $V m$ and $K m$. The jejunal mucosa of nephrotic and control rats had similar ATP content and enzyme activity for lactase, sucrase, maltase and (Na-K)-ATPase and the ratios of RNA to DNA were similar in the nephrotic and control rats. No abnormality of the jejunum was detected by light or electron microscopy. The data suggest that the impairment of absorption is a result of decreased activity of jejunal membrane carrier mechanisms. The altered transport may be secondary to effects related to the metabolic consequences of nephrotic syndrome and does not appear to be related to acute purine aminonucleoside toxicity, edema or malnutrition.
\end{abstract}

\section{Abbreviations}

BUN, blood urea nitrogen

PAN, puromycin aminonucleoside

PEG, polyethylene glycol

The nephrotic syndrome, characterized by proteinuria, hypoproteinemia, and edema is essentially a protein depletion state (4). An experimental nephrotic model has been available since 1955 when Frenk et al. (9) reported that an aminonucleoside of puromycin, a derivative of the antibiotic puromycin, was capable of regularly producing nephrotic syndrome in rats; nevertheless, few investigations have been carried out on intestinal absorption of nutrients in the nephrotic syndrome. In order to help clarify what effect the nephrotic state and its associated metabolic changes might have on intestinal absorption, we evaluated jejunal transport of nutrients in nephrotic rats 14 days after intravenous treatment with purine aminonucleoside. The results were compared to those of pair-fed controls and indicated a generalized decrease in jejunal absorption in the nephrotic rats.

\section{MATERIALS AND METHODS}

Seventy-four adult male Wistar rats (37), weighing 180-200 g, were randomized into experimental and control groups. The nephrotic syndrome was induced in each animal in the experimental group by intravenous injection of $7.5 \mathrm{mg} / 100 \mathrm{~g}$ body weight of
PAN as a $15 \mathrm{mg} / \mathrm{ml}$ solution. The controls were given an equal volume of saline. Control rats were pair-fed by being given the same amount of Purina Lab Chow (38) as their nephrotic counterparts had taken the preceding day. Water intake was allowed ad libitum. Baseline studies were conducted, measuring the daily urine output and the amount of qualitative proteinuria. Intake and weight gain were recorded. Thirteen days after the administration of PAN, 24-h urine protein excretion was quantitated and blood was drawn for serum albumin, BUN, and creatinine.

Fourteen days postinjection, in vivo jejunal transport studies were performed. Groups of four to six experimental and the same number of control animals were studied each time. The rats were anesthetized with urethane (39) administered intraperitoneally at a dose of $1.2 \mathrm{~g} / \mathrm{kg}$. The abdominal cavity was opened by a midline incision and the small intestine was cannulated below the ligament of Trietz. A $20-\mathrm{cm}$ long jejunal segment was utilized and the intestinal contents washed with two $10-\mathrm{ml}$ portions of $0.9 \% \mathrm{NaCl}$ warmed to $37^{\circ} \mathrm{C}$. The proximal junction was attached to a peristaltic pump (40) and the jejunal segment was perfused at a rate of $0.20-0.24 \mathrm{ml} / \mathrm{min}$. The solutions used for perfusion were KrebsHensleit bicarbonate buffers with $1 \mathrm{mM}$ of either histidine, lysine, phenylalanine or glycine and 4-40 mM of glucose. In other experiments, fructose and 3-0 methyl glucose were also perfused. These amounts of nonradioactive substrate, plus three uniformly labeled [H]amino acids and $\left[{ }^{14} \mathrm{C}\right]$-labeled carbohydrates (41) with specific activities above $500 \mu \mathrm{Ci} / \mathrm{mM}$ were added to a level of about $20,000 \mathrm{dpm} / \mathrm{ml}$. In all instances, a nonabsorbable marker, polyethylene glycol (PEG, molecular weight 3000-3700) (42), was added to the buffers in a concentration of $6 \mathrm{~g} /$ liter as an indicator of intestinal water transport. All solutions were made isotonic by adjustment with sodium chloride. The perfusing liquids were bubbled with $\mathrm{O}_{2}: \mathrm{CO}_{2}$ (95:5) and maintained at $37^{\circ} \mathrm{C}$ during the experiments. The abdominal cavity was kept moist and warm by warmed saline soaks and polyurethane wrapping of the abdominal cavity.

Each rat was perfused with buffers containing a single amino acid with $\left[{ }^{3} \mathrm{H}\right]$-labeled tracer and one carbohydrate with $\left[{ }^{14} \mathrm{C}\right]-$ labeled tracer. After a 45 min equilibration period, effluent fractions were collected every $15 \mathrm{~min}$ for $1 \mathrm{~h}$. Immediately afterwards, a second solution with another amino acid and a different concentration of glucose or another carbohydrate was allowed to equilibrate for $\mathbf{3 0} \mathrm{min}$, followed by perfusion for a second hour with fractions collected every $15 \mathrm{~min}$. The sequence of the perfusion buffers was randomized. It took 9-10 min for the solutions to travel the $20-\mathrm{cm}$ segment of the jejunum as measured with phenol red as an indicator.

All fractions collected were cleared of intestinal debris by centrifugation at $600 \times \mathrm{g}$ for $15 \mathrm{~min}$. Each sample was counted for $\left[{ }^{3} \mathrm{H}\right]$ and $\left[{ }^{14} \mathrm{C}\right]$ and the concentrations of electrolytes and PEG determined as indicated below. Transport rates were calculated by comparing the concentrations of the infused buffers and the 
effluents at the end of the $20-\mathrm{cm}$ jejunal segment and correcting for water exchange. The rate of transport of amino acids and carbohydrates was expressed as nmoles absorbed per min per $\mathrm{cm}$ of intestine. The rate of electrolyte transport was expressed as microequivalents absorbed per min per $\mathrm{cm}$ of intestine. The transport of water was calculated by the difference of the volume of the solution infused and recovered from the intestinal segment and their respective concentrations of PEG. The amount of PEG was determined by the method of Malawar and Powell (21).

The concentrations of the amino acids and monosaccharides in the perfusate were determined by isotope dilution (2), counting 0.5 -ml aliquots of the effluent in $10 \mathrm{ml}$ of scintillation fluid (ACSAmersham Searle Inc.). Tritium was counted with an efficiency of at least $10 \%$ and $\left[{ }^{14} \mathrm{C}\right]$ with an efficiency better than $55 \%$ as determined by quenching of an external standard against a calibration curve. All samples were estimated with a statistical error lower than $1 \%$ and a probability better than $99 \%$ in a room temperature operated scintillation counter (Beckman LS-203). At the conclusion of the study the animals were exsanguinated from the abdominal aorta. Sodium and potassium concentrations were determined using a flame photometer Model 143 (43). In addition, protein fractions separated by gel electrophoresis, BUN (44), and creatinine (1) were measured.

The enzymatic activity of the intestinal mucosa was studied at the end of the perfusion period. While the animal was still anesthetized, the entire small intestine was excised and washed with three $10-\mathrm{ml}$ aliquots of $0.99 \%$ ice cold $\mathrm{NaCl}$ solution. A 20$\mathrm{cm}$ long segment of the intestine adjacent to the perfused portion was cut, slit open longitudinally and the mucosa was removed by scraping with a glass slide. The mucosa was weighed and homogenized with nine volumes of ice cold $0.99 \% \mathrm{NaCl}$ for the assay of disaccharidases, or with a buffer containing $250 \mathrm{mM}$ EDTA, 2.4 $\mathrm{mM} \mathrm{Na}$ deoxycholate and $39 \mathrm{mM}$ tris adjusted to $\mathrm{pH} \mathrm{6.8}$. Lactase, sucrase, maltase, ATPase, ATP content, RNA, DNA, RNA/DNA ratio as well as protein content were determined in those specimens. The results are expressed as nmoles of substrate utilized per min per $\mathbf{g}$ of protein or tissue. The activity of intestinal disaccharidases was determined according to Dahlquist (3). ATPase was assayed by the method of Kramer et al. (16). The protein content of the intestinal mucosal homogenates was determined according to Lowry et al. (19) and RNA and DNA estimation according to Schneider (27).

Other portions of the nonperfused jejunum were used for assessment of wet and dry weights as an assay for edema and for histologic and electron microscopic assessment. The wet weight was obtained immediately after sectioning of a $10-\mathrm{cm}$ segment of clean jejunum. It was then compared to the dry weight obtained after dehydration to a constant weight in an oven at $40^{\circ} \mathrm{C}$ for 5 days. For histologic evaluation, the tissue was fixed by immersion in cold $2 \%$ glutaraldehyde and prepared according to standard techniques. For electron microscopy, tissue was fixed by immersion in cold $2 \%$ glutaraldehyde in $0.1 \mathrm{M}$ cacodylate buffer $(\mathrm{pH}$ 7.3) for $1 \mathrm{~h}$, rinsed overnight in cold $0.1 \mathrm{M}$ cacodylate with $7 \%$ sucrose, post-fixed in cold $1 \%$ osmium tetroxide in $0.1 \mathrm{M}$ cacodylate for $1 \mathrm{~h}$, rinsed in cold $7.5 \%$ sucrose, soaked en bloc with uranyl acetate (20), rinsed in cold $7.5 \%$ sucrose, dehydrated in a graded series of ethanols and embedded in Epon (24). Thick sections $(1 \mu \mathrm{m})$ were stained with toluidine blue and examined by light microscopy. Silver-grey thin sections were cut on a PorterBlum MT2-B ultramicrotome and examined on a JEOL-JEM 100 electron microscope.

The differences between the means of the experimental and control groups were compared using the Student's $t$ test (7) and are expressed as means \pm S.E.M.

\section{RESULTS}

The nephrotic model. The nephrotic syndrome was induced in all the experimental animals by an intravenous injection of PAN. The treated animals had anorexia during the first 3-5 days and their food intake was slightly decreased. After the appearance of proteinuria on the 5th day, the experimental rats started gaining weight more than the controls, in spite of equal amounts of food ingested, suggesting the early presence of edema. The peak weight for the nephrotic rats was achieved by the 8th and 9th day, 217 $\pm 5.5 \mathrm{~g}$ (mean \pm S.E.M.) for the nephrotic versus $208 \pm 4.5 \mathrm{~g}$ for the control rats (differences were not significant). From the 9th day, rats given PAN developed diuresis with urinary output rising to a mean of $15.7 \mathrm{ml} /$ day compared to $7.5 \mathrm{ml} /$ day for the controls. By the 14th day postinjection, nephrotic rats weighed less than the controls: $200 \pm 6.0 \mathrm{~g}$ compared to $228 \pm 5.8 \mathrm{~g}$ for the controls $(P<0.01)$. The PAN-injected rats continued to be hypoproteinemic at the time of intestinal perfusion. They had a serum albumin of $1.46 \pm 0.13 \mathrm{~g} / \mathrm{dl}$ versus $2.63 \pm 0.06 \mathrm{~g} / \mathrm{dl}(P<0.001)$ in the controls, and had proteinuria of $0.60 \pm 0.03 \mathrm{~g} / 24 \mathrm{~h}$ compared to $0.05 \pm 0.01 \mathrm{~g} / 24 \mathrm{~h}$ in the control rats. Comparison of the differences between wet and dry weights of jejunal segments of the nephrotic and control rats demonstrated that they were similar in the two groups $(7.86 \mathrm{~g} \pm 0.95$ for nephrotic rats and $8.01 \pm 0.50$ for control rats). The BUN and serum creatinine were in the normal range (BUN, 14-29 mg/dl and creatinine, $0.50-0.60 \mathrm{mg} /$ dl) and similar in both groups 14 days after induction of nephrotic syndrome.

Structure and ultrastructure of intestine. Histologic evaluation and electron microscopic assessment of the jejunum of nephrotic and control rats at the time of perfusion did not show any abnormalities. Jejunal villi from PAN-injected rats were indistinguishable in height from that in controls and there was no evidence of any expansion of the intracellular spaces. Similarly, under the electron microscope, jejunal epithelial cells of PAN-treated rats appeared unremarkable; microvilli were normal in height and contour and all other organelles appeared normal and were indistinguishable from controls.

Transport of carbohydrates. The intestinal absorption of glucose in the nephrotic rats was decreased (Fig. 1). The apparent inhibition of transport was not overcome by increasing the concentration of carbohydrate in the perfusate from $4-40 \mathrm{mM}$. Both the maximum transport capacity and the affinity for the substrate were affected. The kinetic constants $( \pm$ S.E.) obtained according to Wilkinson (33) resulted in a Vm of $81.0 \pm 0.9 \mathrm{nmole} / \mathrm{min} \times \mathrm{cm}$ for the nephrotic rats and $203.2 \pm 7.5 \mathrm{nmole} / \mathrm{min} \mathrm{x} \mathrm{cm}$ for controls, indicating that the decreased rate of glucose transport in the nephrotic animals was not the result of a competitive inhibition phenomenon.

In order to assess whether differences between nephrotic and control glucose utilization at the intestinal mucosa level was a contributing factor in the rate of glucose disappearance from the lumen, the transport of a non-metabolizable analog, 3-0-methyl glucose was studied (Fig. 2). The transport rate of this substance, perfused at $4 \mathrm{mM}$ concentration was also significantly lower in the PAN rats than in controls $(P<0.001)$. But, alterations in

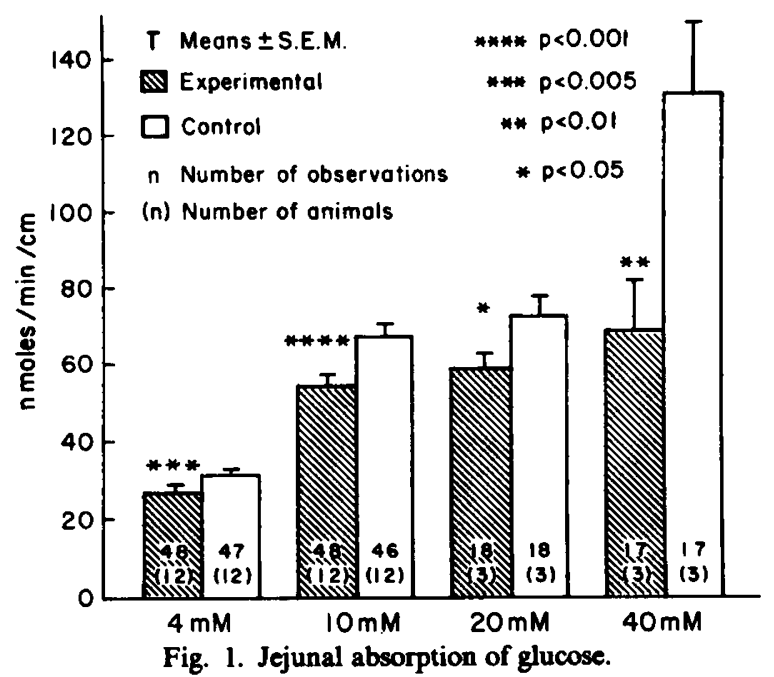


transport were selective because the absorption of fructose was the same in the experimental animals as in the controls (Fig. 2) contrasting with the findings described above.

Transport of amino acids. In general, there was decreased jejunal transport of the amino acids tested in the experimental groups of animals (Fig. 3). The absorption of histidine had the greatest reduction and was $72 \%$ of the control level. The absorption of phenylalanine and glycine was also decreased. The differences between control and nephrotic rats in absorption rates for lysine did not attain significant differences.

Transport of sodium, potassium, and water. The absorption of sodium across the jejunal mucosa of the proteinuric animals was reduced by almost $40 \%$ with a mean \pm S.E.M. of $136.2 \pm 25.1$ $\mu \mathrm{Eq} / \mathrm{min} \times \mathrm{cm}$ in the nephrotic rats, compared to $225.6 \pm 17.9$ $\mu \mathrm{Eq} / \mathrm{min} \times \mathrm{cm}$ in the controls $(P<0.001)$. The number of animals used was the same as those used in the absorption of glucose, 4

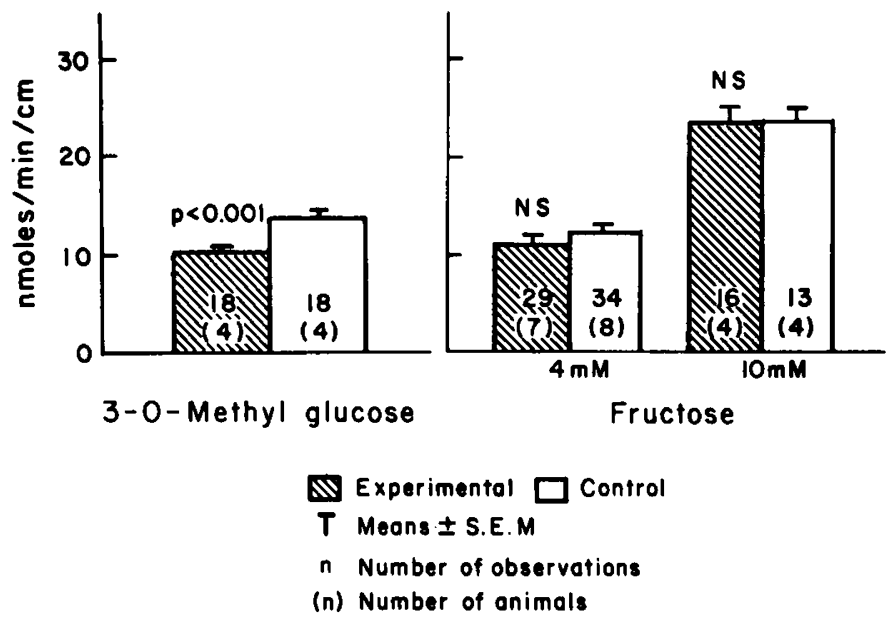

Fig. 2. Jejunal absorption of 3-O-methylglucose and fructose.
mM. Water movement from lumen to cells paralleled the sodium transport and its absorption was reduced in the experimental animals $(1.50 \pm 0.23 \mu \mathrm{l} / \mathrm{min} \times \mathrm{cm}$ in the nephrotics versus $1.71 \pm$ $0.01 \mu \mathrm{l} / \mathrm{min} \times \mathrm{cm}$ in the controls, $P<0.05$ ). No differences were observed in the transport of potassium between control and nephrotic animals.

Enzymes and protein synthesis of the intestinal mucosa. The specific activity of the brush border enzymes sucrase, lactase, and maltase was not altered during the experimental nephrotic syndrome. Similarly, there were no changes in the (Na-K)-ATPase activity, total ATP content or in the RNA/DNA ratio of the jejunal mucosal cells (Table 1).

\section{DISCUSSION}

The jejunal transport of carbohydrates, amino acids, sodium, and water were decreased in the nephrotic rats, but no alterations

Table 1. Jejunal enzyme activity and content ${ }^{1}$

\begin{tabular}{lcc}
\hline \multicolumn{1}{c}{ Enzyme } & Nephrotic & Control \\
\hline Lactase & $0.603 \pm 0.099$ & $0.606 \pm 0.13$ \\
(nmole/min/g protein) & $(17)^{2}$ & $(17)$ \\
Sucrase & $6.835 \pm 0.98$ & $5.916 \pm 0.88$ \\
(nmole/min/g protein) & $(17)$ & $(17)$ \\
Maltase & $7.07 \pm 2.29$ & $4.75 \pm 1.27$ \\
(nmole/min/g protein) & $(17)$ & $(17)$ \\
(Na - K)-ATPase & $36.98 \pm 7.23$ & $26.94 \pm 4.26$ \\
(nmole/min/g protein) & $(16)$ & $(12)$ \\
ATP content & $0.552 \pm 0.041$ & $0.471 \pm 0.058$ \\
(nmole/min/g protein) & $(24)$ & $(16)$ \\
RNA/DNA & $2.95 \pm 0.36$ & $3.67 \pm 0.49$ \\
& $(19)$ & $(15)$ \\
\hline
\end{tabular}

${ }^{1}$ Results are expressed as mean \pm S.E.M. There are no statistically significant differences between nephrotic and control animals.

${ }^{2}(n)$, number of animals.

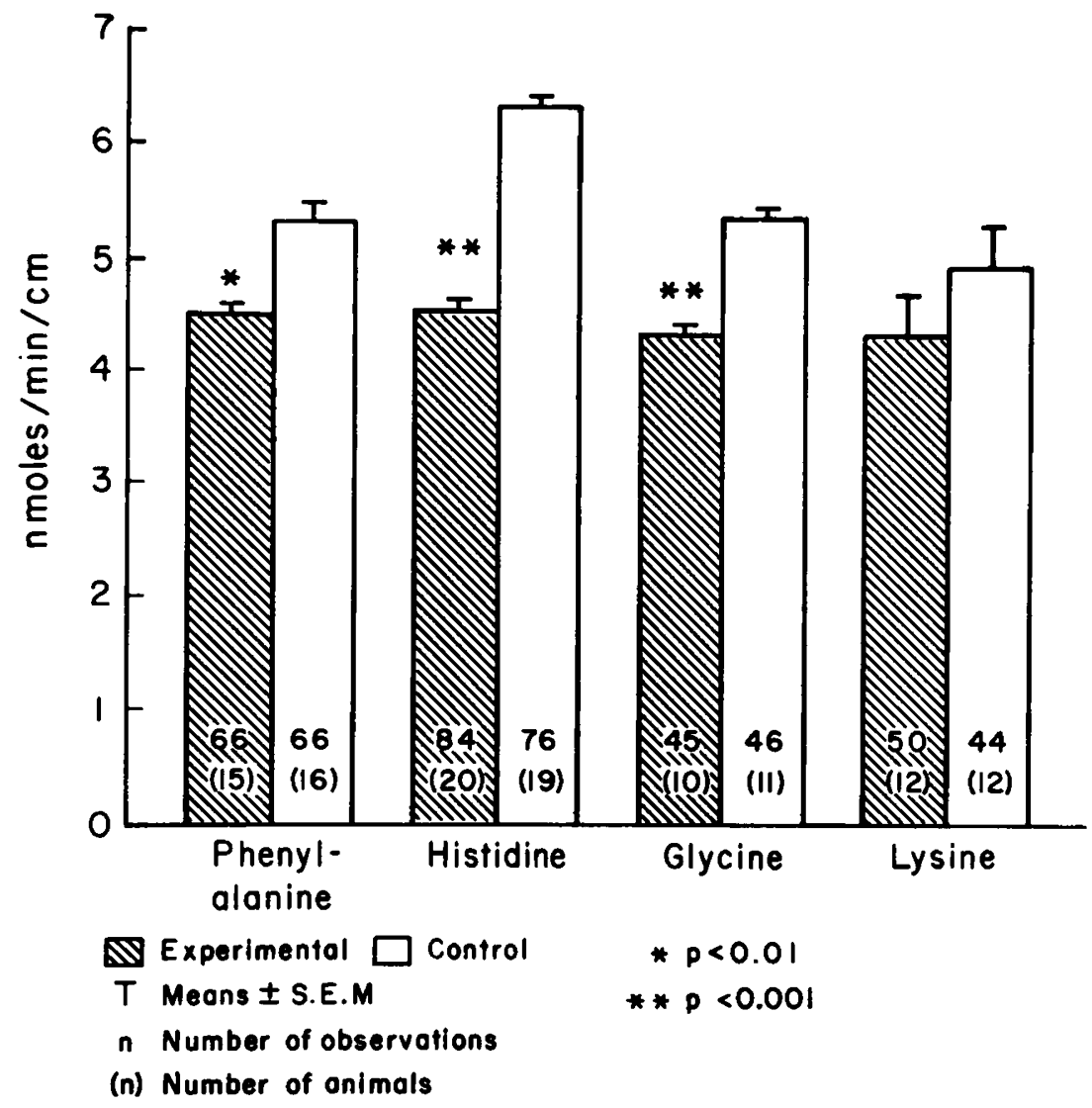

Fig. 3. Jejunal absorption of amino acids. 
of brush border enzymes or (Na-K)-ATPase was found. Similarly, intestinal mucosal protein synthesis as reflected by the ratio of RNA to DNA was not altered. The decreased transport of glucose could be ascribed to effects that altered both the maximum rate of absorption, as well as the affinity of the carrier mechanisms. The overall decreased affinity of the substrate for absorption could occur as a result of a quantitative or qualitative defect in transport sites in the experimental nephrotic syndrome. Decreased absorption rate was also obtained for 3-0-methyl glucose, which is actively transported by the same carrier as glucose (12) but is not metabolized, confirming the carrier as the site of the defect. In contrast, the uptake of fructose, which is transported by a different protein (12), was not altered in the nephrotic animals. Amino acid transport studies also showed a selective inhibition, similar to that observed in carbohydrate transport. At least two of the several active transport systems for amino acids $(26,30,34)$ were impaired in the PAN-treated rats. Glycine, which shares a transport system with iminoacids, and the neutral amino acids, phenylalanine and histidine, showed impaired absorption across the jejunal mucosa. The absorption of the dibasic amino acid lysine, was not statistically different in nephrotic animals.

Movement of water in the intestine generally follows that of sodium. A diminished plasma oncotic pressure secondary to protein depletion might be responsible for the reduced absorption of sodium and water found in the nephrotic rats (29). It is unlikely, however, that decreased plasma oncotic pressure was responsible for the decreased absorption of carbohydrates and amino acids because active transport mechanisms are involved and because other studies in hypoproteinemic malnourished rats have shown increased rather than decreased jejunal absorption $(17,32)$. On the other hand, sodium and water transport are closely linked to that of sugars and amino acids $(8,13)$. It is not surprising therefore, that sodium and water absorption were decreased in the nephrotic rats because absorption of sugars and amino acids was decreased. This was not, however, a generalized disorder of electrolyte transport because the transport of potassium in the nephrotic rats was similar to that in the control rats.

The mechanism for the inhibition of amino acid and carbohydrate transport appears to be unrelated to the acute toxic effects of PAN. Puromycin, the parent compound, and PAN are structurally similar to adenosine, suggesting that they may function as competitive analogs of the latter (6). In vitro studies have shown that PAN causes a decrease in RNA content of cells (31), an effect which was not present in our nephrotic rats at the time of perfusion. Strong inhibition of protein synthesis by puromycin has also been demonstrated in vitro (35) in association with a decrease in active aminoacid transport in a variety of animal cells (23). This occurs within hours after administration of the toxin and is associated with necrotic histologic changes $(5,22)$. Necrotic changes were not found in our experimental rats which were evaluated by light and electron microscopy at the time of perfusion. It has been established that protein synthesis in vivo is inhibited for only a brief period after a single injection of PAN (18), as was given in our study, because the drug is rapidly metabolized by the liver and excreted by the kidneys. In addition, normal values were demonstrated in the jejunal mucosa of the nephrotic rats for disaccharidases, (Na-K)-ATPase activity, ATP content, and ratio of RNA/DNA. The latter reflects the capacity for protein synthesis. These findings argue strongly against a significant toxic effect on protein synthesis to account for the selective inhibition of jejunal absorption that we observed.

It has been speculated that edema of the small intestine and intestinal lymphangiectasia may cause malabsorption in the nephrotic syndrome in patients $(25,36)$. The design of our study excludes the possibility that edema played a role in decreasing transport. Intestinal perfusions were performed on the 14th day when edema was no longer present and the nephrotic animals actually weighed significantly less than the controls. In addition, comparison of wet and dry weights of jejunal segments obtained on the day of perfusion showed no differences between nephrotic and control animals, eliminating the possibility that edema of the intestine played a role in the impaired transport which we observed.

It is not possible from the results of our study to clearly define the mechanism of the decreased jejunal absorption that was observed. The impaired intestinal absorption in our nephrotic animals could be related to catabolic effects of hormones associated with nephrotic syndrome. Recent studies on the metabolic effects of the nephrotic syndrome have shown increased levels of parathyroid hormone secondary to urinary losses of 25-hydroxyvitamin D (11). Parathyroid hormone has been shown to have catabolic effects. King and Stanbury (15) noted that nitrogen balance was frequently negative in patients with primary hyperparathyroidism and other authors have published similar findings (14). In addition, the renal tubular reabsorption of amino acids is known to be decreased by the action of parathyroid hormone (28). Although we did not measure PTH levels in our study, the levels would be expected to be increased in the nephrotic animals. It can be speculated that the catabolic effects of increased PTH combined with the hypoproteinemia of the nephrotic syndrome resulted in depletion of proteins necessary for regeneration of intestinal transport enzymes. Although alterations of transport enzymes secondary to protein depletion would not be expected to be selective, other studies have shown selective alterations of intestinal transport with protein depletion states (32).

The finding of significantly decreased weight in the nephrotic rats at the time of perfusion is of interest. The control animals were pair-fed the same amount of food as was taken spontaneously by the nephrotic rats. Nevertheless, the control rats weighed more than the nephrotics at the time of perfusion. This finding indicates a decreased food efficiency in the nephrotic rats which could be explained, at least in part, by their decreased jejunal absorption. The possibility that malnutrition could be an actual cause for the differences which we found in transport, however, cannot be substantiated. It has been well established that the malnourished rat has increased rather than decreased jejunal absorption of amino acids and carbohydrates $(17,32)$. The same has been shown in man, where it has been demonstrated that malnutrition in the absence of diarrhea is not associated with decreased intestinal absorption (10).

The essential findings in our study of jejunal transport in nephrotic rats are a selective decrease in absorption of carbohydrates and amino acids. These effects are not attributable to the toxic action of PAN nor to edema or malnutrition. They may be the result of a combination of factors that include hormonal alterations and deficiencies of proteins involved in active transport carrier mechanisms.

\section{REFERENCES AND NOTES}

1. Bonsnes, R. W. and Taussky, H. H.: On the colorimetric determination of creatinine by the Jaffe reaction. J. Biol. Chem., 158: 581 (1945).

2. Chase, G. D. and Rabinowitz, J. L.: Principles of radioisotopes methodology. p. 281, Burgess, Minneapolis, Minn. 1962.

3. Dahlquist, A.: Assay of intestinal disaccharidases. Enzym. Biol. Clin., 2: 52 (1970).

4. DeWardener, H. E.: The Kidney 4 th edit. p. 126, (Churchill Livingstone, London 1973).

5. Estensen, R. D. and Baserga, R.: Puromycin induced necrosis of crypt cells of the small intestine of mouse. J. Cell Biol., 30: 13 (1966).

6. Fiegelson, E. B., Drake, J. W., and Recant, L.: Experimental aminon leoside nephrosis in rats. J. Lab. Clin. Med., 50: 437 (1957).

7. Fisher, R. A.: Statistical methods for research workers, Ed. 13, p 114. (Hafner, New York, 1958).

8. Fordtran, J. S.: Stimulation of active and passive sodium absorption by sugars in the human jejunum. J. Clin. Invest., 55: 728 (1975).

9. Frenk, S., Antonowicz, 1., Craig, J. M., and Metcoff, J.: Experimental nephrotic syndrome induced in rats by aminonucleoside. Renal lesions and body electrolyte composition. Proc. Soc. Exp. Biol. Med., 89: 424 (1955).

10. Garcia, S.: Malabsorption and malnutrition in Mexico. Am. J. Clin. Nutrit., 21: 1066 (1968).

11. Goldstein, D. A., Oda, Y., Kurokawa, K., and Massry, S.: Blood levels of 25hydroxyvitamin D in nephrotic syndrome. Ann. Intern. Med., 87: 664 (1977).

12. Gray, G. M.: Carbohydrate digestion and absorption. N. Engl. J. Med., 292: 1255 (1975).

13. Hellier, M. D., Thirumalai, C., and Holdsworth, C. D.: The effect of amino acids and dipeptides on sodium and water absorption in man. Gut, 14: 41 (1973). 
14. Hodgkinson, A.: Biochemical aspects of primary hyperparathyroidism: an analysis of 50 cases. Clin. Sci., 25: 231 (1963).

15. King, R. G. and Stanbury, S. W.: Magnesium metabolism in primary hyperparathyroidism. Ann. Intern. Med., 62: 1223 (1965).

16. Kramer, H. J., Backer, A., and Kruck, F.: Inhibition of Intestinal Na-K-ATPase in experimental uremia. Clin. Chim. Acta, 50: 13 (1974).

17. Lifshitz, F., Hawkins, R. L., Diaz-Bensussen, S., and Wapnir, R. A.: Absorption of carbohydrates in malnourished rats. J. Nutr., 102: 1303 (1972).

18. Longnecker, D. S.: Organ distribution of puromycin in rats. A possible basis for selective cytotoxicity. Lab. Invest., 22: 400 (1970).

19. Lowry, O. H., Rosebrough, N. L., Farr, A. L., and Randall, R. J.: Protein measurements with the Folin phenol reagent. J. Biol. Chem., 193: 265 (1951)

20. Luf, J. M.: Improvements in Epoxy Resin Embedding Methods. 3 J. Biophys. Biochem. Cytol., 2: 409 (1961).

21. Malawar, S. J. and Powell, D. W.: An Improved Turbidometric Analysis of Polyethylene Glycol utilizing an Emulsifier. Gastroenterology, 53: 250 (1967)

22. Nagle, R. B., Bulger, R. E., Stricker, G. E., and Benditt, E. P.: Renal tubular effects of the aminonucleoside of puromycin. Lab. Invest., 26: 558 (1972).

23. Phang, J. M., Valle, D. L., Fisher, L., and Granger, A.: Puromycin effect on amino acid transport: differential rates of carrier protein turnover. Am. J. Physiol., 228: 23 (1975).

24. Sabatini, D. D., Bensch, K., and Barnett, R. J.: Cytochemistry and Electron Microscopy: The preservation of cellular ultrastructure and enzymatic activity by aldehyde fixation. J. Cell Biol., 171: 19 (1963).

25. Salazan de Sousa, J., Guerreiro, O., Cunha, A., and Aranjo, J.: The Association of Nephrotic Syndrome with Intestinal Lymphangiectasia. Archs. Dis. Child., 43: 245 (1968).

26. Saunders, S. J. and Isselbacher, K. J.: Intestinal absorption of aminoacids. Gastroenterology, 50: 586 (1966).

27. Schneider, W. C.: Phosphorus compounds in animal tissues. I. Extraction and estimation of deoxypentose nucleic acid and of pentose nucleic acid. J. Biol. Chem., 161: 293 (1945).

28. Short, E. M., Elsas, L. J., and Rosenberg, L. E.: Effect of parathyroid hormone on renal tubular reabsorption of amino acids. Metabolism, 23: 715 (1974).

29. Sladen, G. E. and Dawson, A. M.: Interrelationships between the absorption of glucose, sodium and water by the normal human jejunum. Clin. Sci., 36: 119 (1969).

30. Spencer, R. P.: Intestinal Absorption of Aminoacids. Am. J. Clin. Nutr., 22: 292 (1969).

31. Suhadolnik, R. J.: Nucleoside Antibiotics p. 43. (Wiley Interscience, New York 1970).

32. Wapnir, R. A. and Lifshitz, F.: Absorption of amino acids in malnourished rats. J. Nutr., 104: 843 (1974).

33. Wilkinson, G. N.: Statistical Estimations in Enzyme Kinetics. Biochem. J., 80: 324 (1961).

34. Wiseman, G.: Absorption of amino acids in "Handbook of Physiology" Code C. F., edit, Section 6, Vol. 3, p. 1277, (Amer Physiol Soc., Washington, D.C., 1968).

35. Yarmolinsky, R. D. and Haba de La, G. L.: Inhibition by puromycin of aminoacid incorporation into protein. Proc. Nat. Acad. Sci., 4S: 1721 (1959).

36. Yssing, M., Jensen, $H$., and Jarnum, S.: Albumin metabolism and gastrointestinal protein loss in children with nephrotic syndrome. Acta Paediatr. Scand., 58: 109 (1969).

37. Charles River, Wilmington, Mass.

38. Purina Lab Chow, Ralston-Purina Co., St. Louis, Mo.

39. Sigma Chemical Corp., St. Louis, Mo.

40. Harvard Instruments, Mills, Mo.

41. New England Nuclear, Coston, Mass.

42. J. T. Barker Co., Phillipsburgh, N.J.

43. Instrumentation Laboratory, Boston, Mass.

44. BUN-TEL, Pfizer, Inc. New York, New York.

45. We gratefully acknowledge the assistance of Kristina Mrozinska, Lori Strand and Rosemary Kenney in the preparation of this manuscript.

46. This investigation was supported in part by a grant from The Shubert Foundation and USPHS - Grant 1 SO 8 RR 09128-01A1.

47. Requests for reprints should be addressed to: Dr. Melinda McVicar, Department of Pediatrics, North Shore University Hospital, 300 Community Dr., Manhasset, N.Y. 11030.

48. Received for publication February 11, 1981.

49. Accepted for publication December 14, 1982.

\title{
Enhancement of Sodium Excretion by Substance $P$ during Saline Loading in the Canine Puppy
}

\author{
ROBERT D. FILDES, ${ }^{(40)}$ MICHAEL SOLHAUG, NICK TAVANI, JR., GILBERT EISNER, \\ PHILIP CALCAGNO, AND PEDRO A. JOSE
}

Department of Pediatrics, Georgetown University Medical Center, 3800 Reservoir Road, N.W., Washington, D.C. 20007, USA

\begin{abstract}
Summary
Saline loading in puppies results in an attenuated natriuresis when compared to the normal response by adult animals to the same degree of volume expansion. To characterize an eventual role for kinins in the diuretic response by puppies to saline loading, two experimental protocols were constructed to evaluate the effect of substance $P$ infusion during baseline hydration and acute saline loading. Low dose $\left(10 \mathrm{ng} \cdot \mathrm{kg}^{-1} \cdot \mathrm{min}^{-1}\right)$ infusion of substance $P$ during basal conditions did not affect urine flow, sodium excretion or glomerular filtration rate (GFR). The addition of saline loading to the ongoing low dose infusion of substance $P$ produced an increase in urine flow from 3.73 to $12 \mu \mathrm{l} \cdot \mathrm{min}^{-1} \cdot \mathrm{g}^{-1}$ kidney weight and resulted in a marked increase in urinary sodium excretion from 110 to $851 \mu \mathrm{Eq} \cdot \mathrm{min}^{-1} \cdot \mathrm{g}^{-1}$ kidney weight. These increases in urine flow and urinary sodium excretion during low dose sub-
\end{abstract}

stance $P$ infusion were significantly greater than those observed during saline loading alone. No significant effect on GFR was observed during either saline loading alone or low dose substance $P$ during saline loading. In Protocol II, the infusion of low dose substance $P$ during an ongoing saline load enhanced diuresis and natriuresis to a greater extent than those receiving only a saline load without affecting GFR. The high dose infusion of substance $P\left(100 \mathrm{ng} \cdot \mathrm{kg}^{-1} \cdot \mathrm{min}^{-1}\right)$ during baseline hydration resulted in a natriuresis and diuresis that persisted during the addition of saline despite a significant fall in GFR. Saline loading alone resulted in increased urinary kallikrein activity and the infusion of substance P $\left(10 \mathrm{ng} \cdot \mathrm{kg}^{-1} \cdot \mathrm{min}^{-1}\right)$ increased urinary kallikrein activity even further. A significant positive correlation between urinary sodium excretion and urine kallikrein activity was found $(r=0.91, P<$ 0.01). 